\title{
Água para Consumo Humano \\ - Perspectivas Gerais sobre as suas Características e o seu Tratamento
}

\author{
LUÍS FILIPE DA COSTA CABEDO E SIMAS*
}

\section{CURIOSIDADES HISTÓRICAS}

Desde os tempos mais remotos que a utilização da água para o seu fim mais nobre, o consumo humano, tem sido feita obedecendo a determinados cuidados. Um texto médico apócrifo datado de 2000 A.C. refere que antes de se consumir água, esta deveria ser fervida, ou aquecida ao sol, ou introduzindo-lhe um ferro em brasa ou então filtrá-la num leito de areia. Estes dados mostram que desde muito cedo o Homem apercebeu-se que a água poderia provocar doenças. Alexandre, o Magno, durante as suas conquistas aconselhava as suas tropas a beber apenas água fervida.

Foi durante o Império Romano, que o abastecimento de água sofreu um grande desenvolvimento tecnológico. Os Romanos construíram captações de água (barragens, poços). aquedutos para efectuar o seu transporte e condutas em pressão feitas de chumbo ou terracota comprimida. Durante o percurso de transporte de água eram feitas bacias de retenção para a remoção de sólidos (decantação). A elevação da água foi outro aspecto que os Romanos desenvolveram utilizando parafusos de Arquimedes, noras, rodas e bombas rudimentares. A utilização da água pelos Romanos atingiu mesmo os aspectos lúdicos (banhos, jogos e fontes para decoração). Já no século II, os caudais afluentes à cidade de Roma atingiam valores de $13 \mathrm{~m}^{3} / \mathrm{s}$, para uma população de cerca de um milhão de habitantes. A queda do Império Romano e as invasões bárbaras levaram a um retrocesso nos desenvolvimentos tecnológicos atingidos no tratamento e abastecimento de água para consumo humano. Só durante o Renascimento, e mais tarde com a Revolução Industrial e o consequente afluxo das populações rurais às cidades, surgiu a necessidade de se desenvolverem sistemas de abastecimento de água e drenagem de águas residuais.

Em meados do século XIX, o médico John Snow conseguiu relacionar um surto de cólera em Londres com a contaminação da água. Ao desligar a bomba manual de um poço verificou uma diminuição do número de casos de cólera, descobrindo posteriormente que o problema estaria num soldado recentemente chegado da Índia e alojado numa pensão cujos esgotos corriam perto do referido poço.

Foi no início do século XX, que se começaram a desenvolver sistemas de desinfecção da água em Inglaterra e nos Estados Unidos da América, introduzindo-se a cloração nos sistemas de abastecimento. Até aos anos setenta, o tratamento efectuado na água tinha como principais objectivos obter uma água isenta de microorganismos patogénicos, sem turvação e quimicamente estável. Para tal utilizava-se o chamado tratamento convencional que consistia numa pré-cloração, coagulação, sedimentação, filtração e cloração final. O desenvolvimento da indústria com a crescente rejeição de efluentes nas linhas de água, e do conhecimento científico com a descoberta de subprodutos dos processos de desinfecção levou a que se procurassem novos processos de desinfecção da água (ozonização, dióxido de cloro ou radiação ultravioleta). No final dos anos oitenta com o crescente aparecimento de compostos cada vez mais complexos com efeitos nefastos para a saúde pública surgiram as filtrações com carvão activado e as ultrafiltrações como forma de assegurar que a população receberia uma água de qualidade.

\section{PRINCIPAIS \\ CARACTERÍSTICAS DAS ÁGUAS}

As águas podem ser classificadas em:

- águas atmosféricas

- águas superficiais doces

- águas subterrâneas

- águas marinhas

\section{a) águas atmosféricas}

As águas atmosféricas são caracterizadas por serem saturadas em oxigénio e azoto e não conterem sais minerais dissolvidos. Podem em regiões industrializadas serem um veículo de transporte de substâncias nocivas (ex: chuvas ácidas).

\section{b) águas superficiais}

As águas superficiais doces são os rios, lagos e albufeiras. As águas dos rios (zona montante) são águas com elevada turvação, pequena contaminação bacteriológica, baixa temperatura e baixos valores de cor. A zona jusante das águas dos rios, devido a estarem geralmente junto de regiões com elevada densidade populacional e industrial, apresenta contaminações significativas aos níveis bacteriológico, orgânico e inorgânico. A cor é também elevada dada a presença de algas e elevadas quantidades de matéria orgânica dissolvida. As águas dos lagos e albufeiras são uma boa fonte de abastecimento de água potável (ex: Barragem de Castelo de Bode). Os lagos e albufeiras funcionam como grandes tanques de sedimentação, o que justifica os baixos valores de cor e turvação das suas águas. Estas águas podem sofrer ao longo do tempo uma perda de qualidade, já que o armazenamento de grandes quantidades de água favorece a decomposição da matéria orgânica e a dissolução de metais (ferro, manganês, cálcio e magnésio). As características destas águas variam com a profundidade (tabela 1). Ao longo do ano as variações são muito lentas, excepção feita a dois curtos períodos no ano, nos quais se dá um fenómeno denominado turnover (mistura rápida das águas), que provoca um aumento brusco da turvação da água, explicado pela estratificação de temperaturas no lago ou albufeira. Durante o Verão as camadas superficiais das águas de um lago ou albufeira aquecem mais rapidamente que as do fundo. No início do Outono, o arrefecimento é mais rápido superficialmente provocando um aumento da densidade da água, que resulta na deslocação das camadas superficiais para o fundo. Durante o inverno ve- 
rifica-se uma diminuição da temperatura de toda a massa de água. Na primavera repete-se o processo, com o aquecimento mais rápido das camadas superficiais. A camada de água mais fria denominada hipolímnio é caracterizada pelo seu baixo teor em oxigénio favorecendo-se por isso o surgimento de organismos anaeróbios. A zona de mudança brusca de temperatura denomina-se metalímnio, enquanto que a camada de água mais quente é o epilímnio. A concentração de oxigénio dissolvido é alterada nesta camada devido aos processos de respiração e fotossíntese das algas. Em determinadas condições (luz solar, temperatura e nutrientes - azoto e fósforo) pode dar-se um crescimento exagerado de algas e outras plantas de acordo com a seguinte equação:

$$
\begin{aligned}
160 \mathrm{CO}_{2}+ & 81 \mathrm{H}_{2} \mathrm{O}+16 \mathrm{NO}_{3}^{-+} \\
+\mathrm{PO}_{4}^{2-}+18 \mathrm{H}^{+} \rightarrow & \mathrm{C}_{106} \mathrm{H}_{181} \mathrm{O}_{45} \mathrm{~N}_{16} \mathrm{P} \text { (material } \\
& +150 \mathrm{O}_{2} \text { celular) }
\end{aligned}
$$

Quando temos a presença de elevados teores de material celular, diz-se que o lago está eutrofizado. Nestas circunstâncias, a água apresenta um aumento dos teores dos parâmetros organolépticos (turvação, cor, cheiro e sabor). Existem vários graus de eutrofização podendo os lagos serem classificados em oligotrófico, mesotrófico e eutrófico, quando a concentração de células de algas por mililitro é de, 1000-2000, 2000-5000 e 5000-20000, respectivamente.

\section{c) águas subterrâneas}

A filtração natural que as águas subterrâneas sofrem no solo contribui para a baixa turvação e a praticamente inexistente contaminação bacteriana. As águas subterrâneas apresentam também uma temperatura constante, um baixo índice de cor e um caudal constante. O contacto que estas águas sofrem com as formações rochosas pode contribuir para uma dureza elevada (presença de iões $\mathrm{Ca}^{2+}$ e $\mathrm{Mg}^{2+}$, principalmente). A baixa percentagem de saturação em oxigénio dissolvido contribui para que estas águas dissolvam metais, essencialmente ferro e manganês.

\section{d) águas marinhas}

As águas marinhas só em condições muito excepcionais serão usadas para a produção de água potável, dados os elevados custos financeiros necessários para a dessalinização da água. Estas águas são caracterizadas essencialmente por terem elevadas concentrações de sais minerais, que podem variar entre $7000 \mathrm{mg} / \mathrm{l}$ (Mar Báltico) a $43000 \mathrm{mg} / \mathrm{l}$ (Mar VermeIho e Golfo Pérsico).

\section{TRATAMENTO DE ÁGUAS PARA CONSUMO HUMANO}

\subsection{Operações de tratamento de águas destinadas a consumo humano}

São vários os procedimentos que se podem executar para ade-

Tabela 1 - Variação dos teores de determinados parâmetros, num lago, a diferentes profundidades

\begin{tabular}{lcccc}
\hline Parâmetro & \multicolumn{4}{c}{ Profundidade $(\mathbf{m})$} \\
\hline & $\mathbf{1}$ & $\mathbf{8}$ & $\mathbf{1 2}$ & $\mathbf{2 0}$ \\
\hline Temperatura $\left({ }^{\circ} \mathrm{C}\right)$ & 25 & 20 & 10 & 10 \\
Saturação em $\mathrm{O}_{2}(\%)$ & 150 & 100 & 25 & 0 \\
$\mathrm{pH}$ & 8.5 & 8.2 & 8.0 & 7.5 \\
Azzoto $(\mathrm{mg} \mathrm{N} / \mathrm{l})$ & 0.05 & 0.10 & 0.8 & 3 \\
Fósforo $(\mathrm{mg} \mathrm{P} / \mathrm{l})$ & 0.02 & 0.05 & 0.20 & 2.0 \\
$\mathrm{H}_{2} \mathrm{~S}(\mathrm{mg} / \mathrm{l})$ & 0 & 0 & 0 & 10 \\
$\mathrm{Fe}$ & & & elevado & elevado \\
$\mathrm{Mn}$ & & & elevado & elevado \\
\hline
\end{tabular}

quar uma água de determinadas características que permitam a sua utilização para consumo humano. Será feita uma descrição desses procedimentos que depois se podem utilizar em conjunto ou isolados, consoante as características da água a tratar.

\subsubsection{Microtamisação}

A microtamisação consiste em fazer passar a água num tambor constituído por uma rede metálica com dimensões que variam entre 0.02 a $0.06 \mathrm{~mm}$, que está parcialmente imerso em água. Este tambor gira com uma velocidade que varia entre os 0.05 e $0.5 \mathrm{~m} / \mathrm{s}$. Utiliza-se a microtamisação essencialmente para remoção de algas em águas superficiais destinadas ao consumo humano.

\subsubsection{Coagulação}

A coagulação é um processo químico utilizado para remover colóides (partículas com dimensões inferiores a $10 \mu \mathrm{m})$. Estes colóides podem ser óxidos metálicos, proteínas de grandes dimensões e microorganismos. A maior parte das partículas coloidais têm carga negativa, o que as impede de se agregarem e poderem ser decantadas. Assim a introdução de um coagulante permite a sua destabilização fazendo com que se agreguem formando flocos de grandes dimensões. Os principais coagulantes utilizados são os sais de ferro e alumínio. Geralmente como adjuvantes deste processo são utilizados os chamados polielectrólitos, que devido às suas longas cadeias moleculares actuam com um mecanismo de formação de pontes inter-partículas.

O processo químico de coagulação que ocorre com os sais metálicos de alumínio é o descrito pela equação 2.

$$
\begin{gathered}
\mathrm{Al}_{2}\left(\mathrm{SO}_{4}\right)_{3}+6 \mathrm{H}_{2} \mathrm{O} \leftrightarrow 2 \mathrm{Al}^{3+}\left(\mathrm{OH}^{-}\right)_{3}+ \\
+6 \mathrm{H}^{+}+3 \mathrm{SO}_{4}^{2 \cdot}(\text { esq. } 2)
\end{gathered}
$$

A adição à água dos sais de alumínio liberta os iões $\mathrm{Al}^{3+}$ que neu- 
tralizam as partículas coloidais (negativas) favorecendo assim a sua coagulação. No entanto, são os hidróxidos de alumínio que resultam da ligação entre os iões $\mathrm{Al}^{3+} \mathrm{e} \mathrm{OH}^{-}$, que sendo insolúveis formam precipitados, constituindo por isso coagulantes mais fortes.

\subsubsection{Floculação}

Depois da destabilização provocada pelos mecanismos de coagulação, as partículas aglomeram-se formando flocos. Os mecanismos utilizados para promover o contacto entre as partículas são dois: movimento browniano (floculação pericinética ou natural) e a utilização de forças exteriores para promover esse contacto (floculação ortocinética). Quando as partículas a flocular têm tamanhos superiores a $1 \mu \mathrm{m}$ a floculação pericinética é muito lenta pelo que se recorre à floculação ortocinética que consiste em provocar turbulência na água utilizando, por exemplo, pás mecânicas.

\subsubsection{Sedimentação}

Geralmente a filtração, rápida ou lenta, é um processo que se utiliza com muita frequência no tratamento de água. No entanto, só funciona com eficiência se a concentração de sólidos suspensos totais for inferior a $5 \times 10^{-3} \mathrm{Kg} / \mathrm{m}^{3}$.

Recorre-se por isso à sedimentação coadjuvada pela coagulação-floculação para diminuir a concentração de sólidos suspensos totais. A sedimentação consiste apenas em deixar depositar as partículas com uma massa específica superior à água. Este processo é tanto mais rápido. quanto maior for o tamanho das partículas a depositar. A água sobrenadante obtida pode então seguir no percurso de tratamento para um filtro, que afinará a sua qualidade em termos de sólidos suspensos.

\subsubsection{Filtração}

A filtração é um processo físico que permite a remoção de sólidos suspensos e a redução do número de bactérias e outros organismos, fazendo passar a água através de um meio poroso. Os leitos destes filtros são geralmente de areia podendo utilizar-se em simultâneo a antracite. Os filtros podem ser rápidos ou lentos, consoante a sua velocidade de filtração podendo ser utilizados isoladamente ou em conjunto, consoante o objectivo pretendido. No entanto, os filtros lentos estão a cair em desuso, uma vez que são precisas áreas muito grandes para os implantar. Contudo, estes filtros têm a vantagem de efectuar um tratamento biológico removendo bactérias e outros microorganismos, o que não acontece nos filtros rápidos. Esta remoção acontece porque dada a baixa velocidade de filtração há formação de um biofilme sobre o leito do filtro. Este biofilme é constituído por uma mistura de algas e bactérias nitrificantes (camada autotrófica), que permitem a remoção do azoto, fósforo e libertação de oxigénio, e por bactérias e outros microorganismos (camada heterotrófica) que removem a matéria orgânica existente na água.

O mecanismo de filtração pode ser descrito como uma combinação de alguns fenómenos, estando descritos a seguir os mais importantes:

- separação mecânica, que consiste na remoção das partículas com dimensões superiores aos poros dos filtros

- sedimentação, que consiste na deposição das partículas com tamanho inferior aos poros na superfície dos grãos de areia por um processo semelhante ao ocorrido na sedimentação

- adsorção do material em suspensão

- actividade química, em que impurezas são decompostas noutras insolúveis, e consequentemente removidas

- actividade biológica, que consiste na utilização de matéria orgânica existente na água por microorganismos

\subsubsection{Amaciamento}

As águas podem classificar-se em:

- águas muito duras (dureza superior a $300 \mathrm{mg} / \mathrm{l}$ de $\mathrm{CaCO}_{3}$ )

- águas duras (dureza entre $150-300 \mathrm{mg} / \mathrm{l}$ de $\mathrm{CaCO}_{3}$ )

- águas moderadamente duras (dureza entre 75-150 mg/l de $\mathrm{CaCO}_{3}$ )

- águas macias ou brandas (dureza inferior a $75 \mathrm{mg} / \mathrm{l}$ de $\mathrm{CaCO}_{3}$ )

Quando uma água tem uma dureza elevada (superior a $150 \mathrm{mg} / \mathrm{l}$ ), pode-se recorrer ao amaciamento ou abrandamento da água, que consiste na remoção total ou parcial dos iões $\mathrm{Ca}^{2+}$ e $\mathrm{Mg}^{2+}$. A necessidade de efectuar esta reduçāo da dureza prendese com alguns inconvenientes das águas duras que são o aumento do consumo de sabão nas lavagens e a precipitação dos iões $\mathrm{Ca}^{2}+$ sob a forma de carbonato de cálcio $\left(\mathrm{CaCO}_{3}\right)$, nas condutas de distribuição da água.

O amaciamento da água pode ser efectuado mediante a utilização de dois processos:

1. precipitação química, que consiste na adição de um composto (cal, carbonato de sódio, soda cáustica) à água, que promova a formação de precipitados de carbonato de cálcio e de hidróxido de magnésio.

$$
\mathrm{Ca}\left(\mathrm{HCO}_{3}\right)_{2}+\mathrm{CaO} \Leftrightarrow 2 \mathrm{CaCO}_{3} \downarrow+\mathrm{H}_{2} \mathrm{O}
$$

2. permuta iónica, que consiste em fazer passar a água por uma resina permutadora de iões que retira os iões $\mathrm{Ca}^{2+} \mathrm{e} \mathrm{Mg}^{2+}$, trocando-os por iões $\mathrm{Na}^{+}$. A resina depois é regenerada fazendo passar contracorrente uma solução concentrada de $\mathrm{NaCl}$.

\subsubsection{Remoção de ferro e manganês}

A presença destes metais na água deve ser evitada não por razões de saúde pública, pois o ferro é um elemento essencial para o meta- 
bolismo humano, mas sim por razões estéticas. Além de conferirem um gosto desagradável à água, mancham os tecidos durante as lavagens e provocam a formação de precipitados nas condutas de distribuição da água, favorecendo o desenvolvimento de ferrobactérias (massa gelatinosa causadora de um aumento de turvação da água). O mecanismo de remoção consiste em transformar formas solúveis destes metais ( $\mathrm{Fe}^{2+}$ e $\mathrm{Mn}^{2+}$ ) em formas insolúveis ( $\mathrm{Fe}^{3+}$ e $\mathrm{Mn}^{4+}$ ). Tal consegue-se promovendo-se uma oxidação por arejamento, por exemplo, seguido de uma decantação e filtração para a remoção dos precipitados formados segundo as equaçōes químicas seguintes:

$$
\begin{array}{r}
4 \mathrm{Fe}^{2+}+\mathrm{O}_{2}+10 \mathrm{H}_{2} \mathrm{O} \Leftrightarrow 4 \mathrm{Fe}(\mathrm{OH})_{3} \downarrow+8 \mathrm{H}^{+} \\
\text {(eq. } 4) \\
6 \mathrm{Mn}^{2+}+3 \mathrm{O}_{2}+6 \mathrm{H}_{2} \mathrm{O} \Leftrightarrow 6 \mathrm{MnO}_{2} \downarrow+12 \mathrm{H}^{+}
\end{array}
$$
(eq. 5)

\subsubsection{Estabilização}

Muitas destas operações de tratamento, como é visível nas equações apresentadas podem alterar o $\mathrm{pH}$ da água, sendo necessário por vezes ajustá-lo para que a água não śeja nem agressiva nem incrustrante. A correcção da agressividade pode ser efectuada fazendo a água passar por um leito de brita calcária, eliminando o $\mathrm{CO}_{2}$ em excesso transformando-o em hidrogenocarbonatos solúveis $\left(\mathrm{HCO}_{3}^{-}\right)$

$\mathrm{CaCO}_{3}+\mathrm{CO}_{2}+\mathrm{H}_{2} \mathrm{O} \Leftrightarrow \mathrm{Ca}^{2+}+2 \mathrm{HCO}_{3}-$ (eq. 6 )

ou então, por adição de cal viva ou apagada ou carbonato de sódio, por exemplo.

$$
\begin{gathered}
\mathrm{CaO}+2 \mathrm{CO}_{2}+\mathrm{H}_{2} \mathrm{O} \Leftrightarrow \mathrm{Ca}\left(\mathrm{HCO}_{3}\right)_{2} \text { (eq. 7) } \\
\mathrm{Ca}(\mathrm{OH})_{2}+2 \mathrm{CO}_{2} \Leftrightarrow \mathrm{Ca}\left(\mathrm{HCO}_{3}\right)_{2} \text { (eq. 8) } \\
\mathrm{Na}_{2} \mathrm{CO}_{3}+\mathrm{CO}_{2}+\mathrm{H}_{2} \mathrm{O} \Leftrightarrow 2 \mathrm{NaHCO}_{3} \text { (eq. 9) }
\end{gathered}
$$

Quando uma água é incrustrante consegue-se a diminuição de $\mathrm{pH}$ mediante a adição de ácido carbónico (recarbonatação), ou então acidificando com os ácidos sulfúrico ou clorídrico (acidificação).

\subsubsection{Desinfecção}

A desinfecção será porventura a operação comum a todos os esquemas de tratamento de água, independentemente das suas características e origem. A necessidade de eliminar os possíveis microorganismos patogénicos que a água possa transportar levou a que várias tecnologias de desinfeç̧ão fossem desenvolvidas. Actualmente, as tecnologias de desinfecção de águas mais usadas são as que utilizam o cloro (nas suas diversas formas), ozono e radiação UV. O cloro é o agente desinfectante mais utilizado em todo o Mundo (cerca de $80 \%$ das desinfecções). As grandes desvantagens deste agente são a formação de compostos organoclorados (trihalometanos, que são compostos potencialmente cancerígenos), a formação de clorofenóis que provocam odores desagradáveis e o facto de não ser suficientemente forte para eliminar, por exemplo, os vírus. $\mathrm{O}$ cloro pode ser utilizado nas formas gasosas $\left(\mathrm{Cl}_{2}\right)$, hipocloritos de sódio e cálcio $\left(\mathrm{NaOCl}\right.$ e $\left.\mathrm{Ca}(\mathrm{OCl})_{2}\right)$ e dióxido de cloro $\left(\mathrm{ClO}_{2}\right)$. As reaç̧ões das diversas formas de cloro com a água estão esquematizadas nas equações seguintes:

$$
\mathrm{Cl}_{2}+\mathrm{H}_{2} \mathrm{O} \rightarrow \mathrm{HOCl}+\mathrm{Cl}^{-}+\mathrm{H}^{+} \text {(eq. 10) }
$$

$\mathrm{NaOCl}+\mathrm{H}_{2} \mathrm{O} \rightarrow \mathrm{HOCl}+\mathrm{Na}^{+}+\mathrm{OH} \cdot($ eq. 11$)$

$$
\mathrm{Ca}(\mathrm{OCl})_{2}+\mathrm{H}_{2} \mathrm{O} \rightarrow 2 \mathrm{HOCl}+\mathrm{Na}^{2+}+2 \mathrm{OH}^{-}
$$

O ácido hipocloroso (HOCl) decompõe-se segundo a seguinte equação:

$$
\mathrm{HOCl} \Leftrightarrow \mathrm{OCl}^{-}+\mathrm{H}^{+}(\text {eq. 13) }
$$

Tanto o ácido hipocloroso ( $\mathrm{HOCl})$ como o ião hipoclorito $\left(\mathrm{OCl}^{-}\right.$ ) actuam como desinfectantes, sendo no entanto, o primeiro cerca de 80 vezes mais eficiente do que o segundo. Esta dissociação do ácido hipocloroso é dependente do $\mathrm{pH}$ da água. Assim, quanto mais alcalina é uma água menor é a capacidade de desinfecção já que o grau de dissociação da equação 7 é muito elevado.

O cloro permite a manutenção de um residual que garante a eliminação de eventuais contaminações que possam surgir no percurso de distribuição da água. A presença da amónia $\left(\mathrm{NH}_{4}{ }^{+}\right)$na água promove a formação de cloraminas ao reagir com o $\mathrm{HOCl}$ :

$$
\begin{gathered}
\mathrm{NH}_{4}{ }^{+}+\mathrm{HOCl} \rightarrow \mathrm{NH}_{2} \mathrm{Cl}+\mathrm{H}_{2} \mathrm{O}+\mathrm{H}^{+} \text {(eq. 14) } \\
\mathrm{NH}_{2} \mathrm{Cl}+\mathrm{HOCl} \rightarrow \mathrm{NHCl}_{2}+\mathrm{H}_{2} \mathrm{O} \text { (eq. 15) } \\
\mathrm{NHCl}_{2}+\mathrm{HOCl} \rightarrow \mathrm{NCl}_{3}+\mathrm{H}_{2} \mathrm{O} \text { (eq. 16) }
\end{gathered}
$$

Assim, temos a formação respectivamente, de monocloraminas $\left(\mathrm{NH}_{2} \mathrm{Cl}\right)$, dicloraminas $\left(\mathrm{NHCl}_{2}\right)$ e tricloraminas $\left(\mathrm{NCl}_{3}\right)$. As monocloraminas e dicloroaminas também têm poder desinfectante, embora mais fraco que o ácido hipocloroso e o ião hipoclorito. No entanto, o seu poder desinfectante é muito duradouro pelo que nalgumas estações de tratamento é adicionada juntamente com o cloro, a amónia.

O ozono tem propriedades oxidantes muito fortes e uma vez que não provoca nem odores nem sabores tem sido utilizado em substituição do cloro, embora seja uma técnica de desinfecção mais cara. Outras vantagens do ozono são a possibilidade de se combinar com o ferro e manganês formando-se hidróxidos insolúveis, mais fáceis de remover; a capacidade de neutralizar compostos tóxicos como cianetos e fenóis e a sua elevada reactividade com compostos orgânicos. O ozono em combinação com carvão activado permite reduzir cor, cheiro, sabor e microorganismos utilizando doses de $1 \mathrm{mg} / \mathrm{l}$, com tempo de contacto de 10 minutos. Além de ser uma tecnologia mais dispendiosa, o ozono não deixa um residual, pelo que para prevenir o aparecimento de microorganismos durante a distribuição de água pode fazer-se uma cloragem de baixos níveis. Se uma água contiver brometos a utilização de ozono, origina a formação de 
bromatos, composto este que segundo a Organização de Mundial de Saúde (O.M.S.) é carcinogénico. A O.M.S. também refere que este composto não deve estar na água em concentrações superiores $1 \mu \mathrm{g} / \mathrm{l}$. A remoção do bromato só pode ser feita utilizando uma filtração com membrana, que é também muito dispendiosa.

A outra alternativa em termos de desinfecção de águas é a radiação UV. Consegue-se com lâmpadas que emitem radiação de comprimentos de onda que variam entre os 250 e 265 nm. Estas lâmpadas encontramse dentro de câmaras de aço inoxidável. É um método realmente efectivo, mas só pode ser usado em sistemas de distribuição muito pequenos em que a probabilidade de contaminação seja muito pequena, podendo também ser utilizado ao nível doméstico.

\subsection{Esquemas de tratamento de águas destinadas a consumo humano}

Geralmente e salvo determinadas excepções, a água existente na Natureza que é utilizada para consumo humano, tem que sofrer um esquema de tratamento adequado às suas características, que podem ser determinadas mediante a sua análise. As águas utilizadas para abastecimento são na esmagadora maioria águas superficiais doces e águas subterrâneas. Seguidamente serão apresentados alguns esquemas possíveis de tratamento de águas subterrâneas, que dadas as suas características exigem tratamentos pouco complexos.

O esquema da figura 1 será para uma água que naturalmente possua boas características, sendo necessária apenas uma desinfecção como prevenção para eventuais contaminações que possam surgir no percurso de distribuição. Como foi referido no ponto 2 , as águas subterrâneas dissolvem metais com muita facilidade pelo que a sua remoção poderá ser feita com o tratamento esquematizado na figura 2 . Na figura 3, o tratamento esquematizado destina-se a uma água muito dura, isto é, com elevadas concentrações de cálcio e magnésio.

As águas superficiais têm um esquema de tratamento mais complexo dos quais se apresenta um exemplo de tratamento de água de uma albufeira ou lago, tendo em vista o consumo humano (figura 4).

Estes esquemas de tratamento consistem em várias operações que devem ser definidas de acordo com as características da água a utilizar para abastecimento.

Durante a distribuição a água
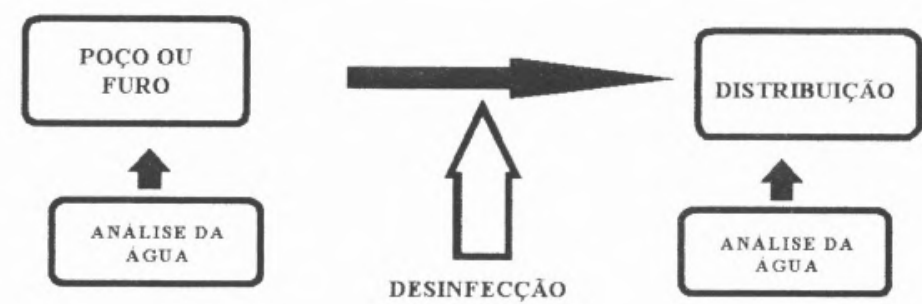

Fig. 1 - Desinfecção da água captada

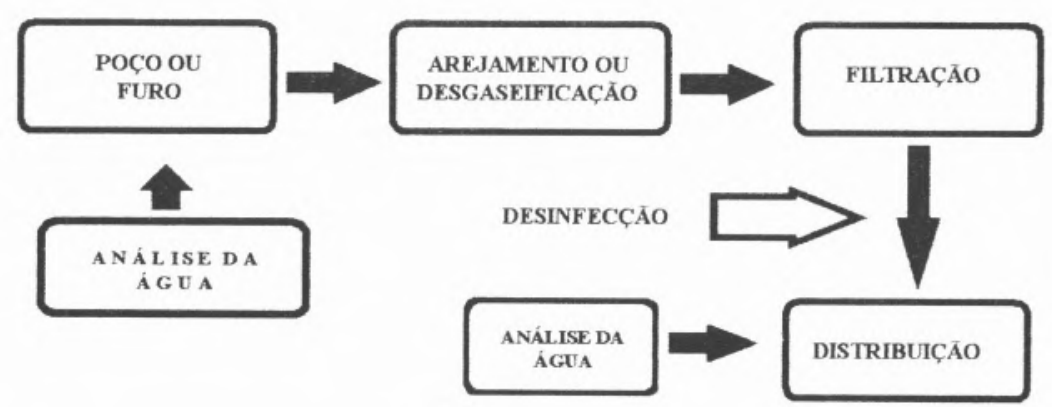

Fig. 2 - Remoção de ferro e manganês 


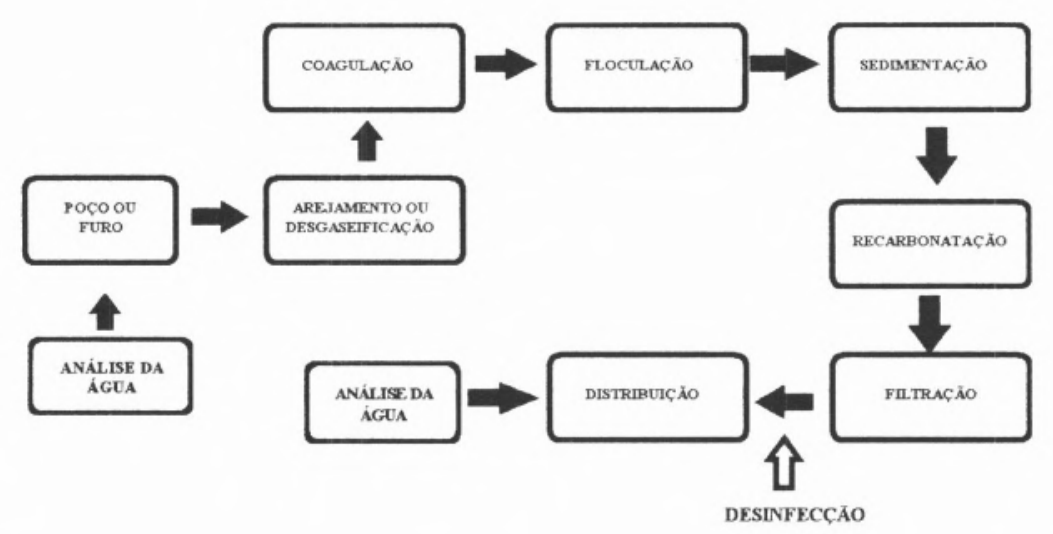

Fig. 3 - Abrandamento por precipitação

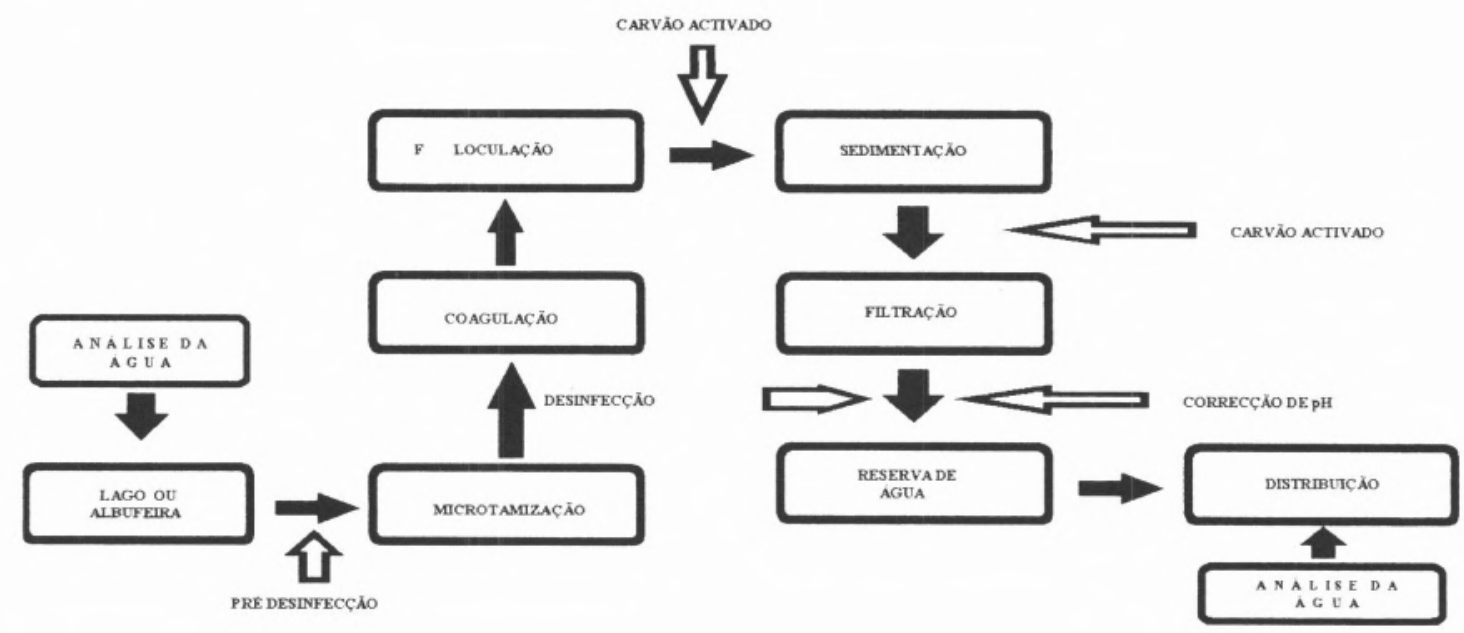

Fig. 4 - Tratamento de água de um lago ou albufeira

deve ser analisada com a frequência estabelecida no diploma legal criado para o efeito (Decreto-Lei 74/90, de 7 de Março). Neste diploma constam os parâmetros a analisar consoante a origem da água e o fim a que se destina (recreativos, piscícolas, rega, consumo humano e águas residuais); os valores máximos recomendáveis (VMR) e admissíveis (VMA) e no caso da água se destinar ao consumo humano o número e a frequência das análises a realizar de acordo com o número de consumidores a abastecer.

\section{CONCLUSÃO}

Para que se possa fazer um cor- recto tratamento de uma determinada água destinada ao consumo humano, além de um conhecimento profundo de todos os fenómenos físicos e químicos que estão envolvidos nas diferentes operações de tratamento, é necessário que a Estação de Tratamento de Água (ETA) tenha sido correctamente dimensionada.

É por esta razão, que pessoalmente acredito na necessidade da constituição de equipas pluridisciplinares que permitam uma abordagem de todos os problemas relacionados com o tratamento da água e com a construção das infraestruturas suportes da ETA.
Técnico Superior dos Serviços Municipalizados de Santarém, licenciado em Bioquímica, Pós Graduado em Qualidade da Água e Controlo de Poluição pela Universidade de Coimbra - Serviços Municipalizados de Santarém Praça Visconde Serra do Pilar 2000 SANTARÉM (tel: $043-$ 3005050; fax: 043-3005051)

\section{BIBLIOGRAFIA}

N. F. Gray, Drinking Water Quality - problems and solutions, John Wiley \& Sons, 1996

I. M. Vieira, Tratamento de Água de Abastecimento, Aponta. mentos para o Mestrado em Hidraúlica e Recursos Hidricos da Universidade de Coimbra, 1997

Decreto-Lei 74/90, 7 de Março 